\title{
Cardiovascular effects of an intravenous bolus of morphine in the ventilated preterm infant
}

\author{
N Rutter, N Evans
}

\begin{abstract}
Aim-To examine the cardiovascular effects of an intravenous bolus of morphine, $100 \mu \mathrm{g} / \mathrm{kg}$, in 17 ventilated preterm infants. Methods-Heart rate and blood pressure were monitored. Right ventricular output, superior vena caval flow, and the width of the ductus arteriosus were measured by Doppler echocardiography 10 and $60 \mathrm{~min}-$ utes after the morphine injection, and the values compared with baseline values by the paired $t$ test.

Results-There was a small but significant fall in heart rate $(2.1 \%$ at 10 minutes, $4.3 \%$ at 60 minutes) consistent with a sedative effect. There was no effect on systolic, diastolic, or mean blood pressure. There was no significant effect on systemic blood flow as measured by either right ventricular output or superior vena caval flow. Ductal width was significantly reduced by a mean of $16 \%$ at 60 minutes, suggesting that normal duct closure was not inhibited.
\end{abstract}

Conclusion-No cardiovascular effects of an intravenous bolus of morphine could be detected.

(Arch Dis Child Fetal Neonatal Ed 2000;83:F101-F103)

Keywords: preterm; opiate; morphine; analgesia; sedation; cardiovascular

Intravenous opiates are now widely used to provide analgesia and sedation in ventilated newborn infants. They appear to be effective, as judged by modification of behaviour, physiological variables, and the hormonal stress response. ${ }^{12}$ Although they are generally considered to be safe, several studies have reported a small but statistically significant fall in mean arterial blood pressure following the administration of both morphine and diamorphine. ${ }^{1-5}$ To minimise this small hypotensive effect, it is usually recommended that the initial loading dose is infused slowly over a period of up to two hours.

Such a recommendation is unsatisfactory for two reasons. Firstly, there are circumstances in newborn intensive care where it is desirable to provide instant sedation and analgesia by giving a bolus injection of opiate. Secondly, it is based on the assumption that a fall in blood pressure represents a deterioration in health. Although this may be so for profound hypotension, blood pressure has been shown to be an unsatisfactory measure of cardiac output in the newborn. ${ }^{6}$

Little is known about the direct cardiovascular effects of intravenous opiates in the new- born and no information is available on the effects of a bolus injection. We therefore carried out the following study to determine the cardiovascular effects of a bolus injection of morphine in a group of ventilated newborn infants.

\section{Subjects}

Infants were eligible for inclusion in the study if they were intubated and ventilated from birth, if they had indwelling arterial lines for direct measurement of blood pressure, and if they had not been exposed to opiates in pregnancy or during delivery. Seventeen infants (eight boys) were studied. Their median gestational age was 27.0 weeks (range 24-32) and median birth weight $1.03 \mathrm{~kg}$ (range 0.56-1.80). At the time the morphine was given, the median age was 3.1 hours (range 2.3-5.3). Nine had respiratory distress syndrome, of whom eight received their first dose of surfactant before the study. The remaining infants were ventilated for immaturity alone. The median $\mathrm{FIO}_{2}$ was 0.25 (range 0.21-0.97); seven infants were breathing air at the time of study. The median mean airway pressure was $10 \mathrm{~mm} \mathrm{Hg}$ (range 6-13). Infants were studied with the written consent of a parent and the study was approved by the Central Sydney Area Health Service ethics review committee.

\section{Methods}

On admission to the neonatal intensive care unit, the infant was stabilised, lines were inserted, blood gas levels were determined and ventilator settings adjusted accordingly, a chest radiograph was obtained, and surfactant given if indicated. A baseline set of physiological measurements was then carried out. An intravenous bolus of morphine at a dose of 100 $\mu \mathrm{g} / \mathrm{kg}$ body weight was given and the measurements were repeated 10 and 60 minutes later. During the time the infant was being studied, no inotropes or volume expansion were given. The following measurements were carried out at each of the three defined times.

(1) Heart rate was recorded from the ECG monitor. Systolic, diastolic, and mean arterial blood pressure were measured directly by a pressure transducer connected to the arterial line. In 10 of the 17 infants, recordings of heart rate and blood pressure were made at one minute intervals, starting 30 minutes before and finishing 60 minutes after the morphine was given, and downloaded to a central database (Docvue; Hewlett-Packard, Palo Alto, California, USA) so that trends in blood 
Table 1 Mean (SD) values for the physiological variables before and 10 and 60 minutes after an intravenous bolus of morphine

\begin{tabular}{llll}
\hline & Baseline & 10 minutes & 60 minutes \\
\hline Heart rate (beats/min) & $145(12)$ & $142(10)$ & $139(13)$ \\
Systolic BP (mm Hg) & $39.5(7.5)$ & $38.5(8.6)$ & $38.9(6.4)$ \\
Diastolic BP (mm Hg) & $23.8(6.2)$ & $24.1(6.3)$ & $23.9(5.9)$ \\
Mean BP (mm Hg) & $30.6(6.6)$ & $30.4(7.1)$ & $30.5(6.0)$ \\
RVO $(\mathrm{ml} / \mathrm{kg} / \mathrm{min})$ & $180(50)$ & $168(43)$ & $171(64)$ \\
SVCF $(\mathrm{ml} / \mathrm{kg} / \mathrm{min})$ & $86(28)$ & $82(25)$ & $84(35)$ \\
Duct size $(\mathrm{mm})$ & $2.1(0.6)$ & $2.0(0.6)$ & $1.8(0.6)$ \\
\hline
\end{tabular}

$\mathrm{BP}$, blood pressure; RVO, right ventricular output; SVCF, superior vena caval flow.

Table 2 Mean (SD) of the individual percentage changes in physiological parameters at 10 and 60 minutes compared with baseline values

\begin{tabular}{lll}
\hline & 10 minutes & 60 minutes \\
\hline Heart rate & $-2.1(3.2)^{\star}$ & $-4.3(5.3)^{\star \star}$ \\
Systolic BP & $-2.8(7.9)$ & $-0.6(11.3)$ \\
Diastolic BP & $+1.1(5.8)$ & $+1.0(9.4)$ \\
Mean BP & $-1.0(6.5)$ & $+0.4(10.3)$ \\
RVO & $-5.5(13.4)$ & $-3.3(28.0)$ \\
SVCF & $-2.2(19.4)$ & $+1.4(38.9)$ \\
Duct size & $-2.7(16.5)$ & $-15.9(15.9)^{\star \star}$ \\
${ }^{\star} \mathrm{p}<0.05,{ }^{\star \star} \mathrm{p}<0.005$. &
\end{tabular}

pressure could be observed. In the remaining seven, the baseline, 10, and 60 minute values only were recorded.

(2) Systemic blood flow was measured in two ways. Right ventricular output (RVO) is a good measure of total cardiac output in the newborn because it is unaffected by the left to right ductal shunt which is invariably present in the early neonatal period. However, because RVO can be confounded by a left to right shunt through a patent foramen ovale, ${ }^{7}$ superior vena caval flow (SVCF) was also measured. This measures the return of venous blood to the right atrium through the superior vena cava, reflecting the cardiac output that goes mainly to the head. Both were measured by Doppler echocardiography by techniques that have been described previously. ${ }^{8-10}$ The intraobserver reliability for SVCF measurement is $8 \% .{ }^{10}$ Echocardiography was performed by one of us with an Acuson 128/XP10 scanner and a $7 \mathrm{MHz}$ transducer. The scan was recorded on videotape and measurements made later from the tape.

(3) As duct closure may be affected by opiates, duct size was assessed by measurement of the width of the Doppler colour signal at its narrowest point when imaged in the longitudinal view. ${ }^{7}$ The shunt direction was analysed by pulsed Doppler.

\section{Statistical analysis}

The physiological data were normally distributed. The value of each variable at 10 and 60 minutes was compared with the baseline value using a paired $t$ test.

\section{Results}

Table 1 gives the mean values for the physiological variables, and table 2 gives the mean percentage change at 10 and 60 minutes from baseline values.
There was a small but statistically significant fall in heart rate at 10 and 60 minutes. Changes in systolic, diastolic, and mean blood pressure were examined in three ways. When point measurements at 10 and 60 minutes were compared with baseline values in all 17 infants, there were no significant changes. In the 10 infants for whom serial measurements were taken, blood pressure was averaged over 10 minute periods leading up to each of the three measurement points; again no significant changes were shown. In each of these 10 infants, the time plot of systolic, diastolic, and mean blood pressure was examined visually. No change could be seen in response to the bolus injection of morphine.

RVO fell by $6 \%$ at 10 minutes and was 3\% below baseline values at 60 minutes, but these falls were not statistically significant. No significant changes were seen in SVCF. Overall values of RVO and SVCF remained within our normal range for preterm infants of this age.

There was a highly significant reduction in duct diameter in the hour after the morphine was given (mean 16\% fall from baseline value; $\mathrm{p}<0.005$ ). In all cases the shunt direction was either solely or predominantly from left to right and unaffected by morphine.

\section{Discussion}

Intravenous morphine given as a bolus to healthy adults has a vasodilator effect and acts particularly on the venous system. ${ }^{11}{ }^{12}$ It has little or no effect on mean arterial blood pressure but improves systemic blood flow by reducing vascular resistance. It does, however, impair the normal compensatory mechanisms that maintain arterial blood pressure in the upright position and in the presence of hypovolaemia. ${ }^{11}$ The venodilator action is thought to be through the central nervous system, ${ }^{12}{ }^{13}$ although there may be a peripheral vascular action caused directly by the opiate or indirectly by histamine release. In adults with cardiovascular disease, there may be a transient fall in blood pressure, but cardiac output is either improved or unchanged, not reduced..$^{14}$

Previous studies of intravenous morphine in the preterm ventilated newborn have shown a small fall in mean arterial blood pressure (from 2 to $4 \mathrm{~mm} \mathrm{Hg}$ ) when the drug is given as an infusion over two hours in a dose of 100 or 200 $\mu \mathrm{g} / \mathrm{kg} .{ }^{1-3}$ Sabatino et al $l^{2}$ studied the haemodynamic effects of a $100 \mu \mathrm{g} / \mathrm{kg}$ dose of morphine infused over two hours in 30 preterm infants. They measured cerebral blood flow velocity and left ventricular output before and during the infusion, and found no significant changes. Left ventricular output, however, is an unreliable measure of cardiac output as most ventilated preterm infants on the first day of life will have a ductal shunt that is mainly or wholly left to right. $^{8}$

This is the first study of the effects of a bolus injection of opiate in the newborn. We have shown a small but statistically significant reduction in heart rate following an intravenous bolus of morphine, consistent with its sedative effect. We have failed to show any other cardiovascular action. The effect on 
systemic arterial blood pressure (systolic, diastolic, and mean) was examined in a number of ways, but no significant effect of the morphine bolus was shown. There was no evidence of a fall in systemic blood flow. RVO showed a small non-significant fall but values were well within the normal range for infants of this gestation and age. SVCF (to which cerebral blood flow is the major contributor ${ }^{16}$ ) was unchanged.

This study was uncontrolled - that is, there was no parallel untreated group for comparison of the cardiovascular variables. It is possible therefore that a hypotensive or cardiodepressant action of morphine was masked by the effect of time because blood pressure and cardiac output in preterm infants tend to increase in the early newborn period. We think, however, that this is unlikely. The morphine was given as a rapid bolus over a few seconds and the effects were sought 10 and 60 minutes later. It is within this period that any cardiovascular effect of morphine would be expected to occur. Vasoactive drugs given as an intravenous bolus should exert their effects very quickly. In several respects, this study represents the worst case situation for demonstrating cardiovascular side effects of an intravenous opiate. The drug was given rapidly to a very immature group of infants who were studied very soon after birth at a time of cardiovascular adaptation, yet no effects could be seen. The number of infants studied was not large, so a small cardiovascular effect or an uncommon idiosyncratic reaction to the morphine injection could not be ruled out.

It is theoretically possible that intravenous morphine impairs closure of the ductus arteriosus by a direct action on the muscle of the ductal wall. This has not been examined before but we found no evidence of it. There was a highly significant reduction in ductal width of $16 \%$ over the one hour study period with no alteration in the nature of the ductal shunt, which remained wholly or mainly from aorta to pulmonary artery. This is consistent with the natural history of spontaneous duct closure in this group of infants. ${ }^{17}$

The study does not support the recommendation that a $100 \mu \mathrm{g} / \mathrm{kg}$ loading dose of morphine has to be infused slowly over two hours. There may be no particular advantage in giving it either slowly or quickly in an infant who is already being ventilated. However, if sedation and analgesia is needed instantly, for example during semielective intubation in an infant with worsening respiratory distress or recurrent apnoea, then a bolus injection seems to be an appropriate and safe way of providing it.

1 Quinn MW, Wild J, Dean HG, et al. Randomised double-blind controlled trial of effect of morphine on catecholamine concentrations in ventilated pre-term babies. Lancet 1993;342:324-7.

2 Sabatino G, Quartulli L, Di Fabio S, Ramenghi LA. Hemodynamic effects of intravenous morphine infusion in ventilated preterm babies. Early Hum Dev 1997;47:263-70.

3 Wood CM, Rushforth JA, Hartley R, Dean H, Wild J, Levene MI. Randomised double blind trial of morphine versus diamorphine for sedation of preterm neonates. Arch Dis Child Fetal Neonatal Ed 1998;79:F34-9.

4 Elias-Jones AC, Barrett DA, Rutter N, Shaw PN, Davis SS. Diamorphine infusion in the preterm neonate. Arch Dis Child 1991;66:1155-7.

5 Barker DP, Simpson J, Pawula M, Barrett DA, Shaw PN, Rutter N. Randomised double-blind trial of two loading dose regimens of diamorphine in ventilated newborn infants. Arch Dis Child Fetal Neonatal Ed 1995;73:F22-6.

6 Kluckow M, Evans N. Relationship between blood pressure and cardiac output in preterm infants requiring mechanical ventilation. F Pediatr 1996;129:506-12.

7 Evans N. Iyer P. Assessment of ductus arteriosus shunt in preterm infants supported by mechanical ventilation:
effects of interatrial shunting. F Pediatr 1994;125:778-85.

8 Sholler GF, Celermajer JM, Whight CM, Bauman AE. Echo Doppler assessment of cardiac output and its relation to growth in normal infants. Am f Cardiol 1987;60:1112-16.

9 Evans N, Kluckow M. Early determinants of right and left ventricular output in ventilated preterm infants. Arch Dis Child Fetal Neonatal Ed 1996;74:F88-94.

10 Kluckow M, Evans N. Superior vena cava flow in newborn infants: a novel marker of systemic blood flow. Arch Dis Child Fetal Neonatal Ed 2000;82:F182-7.

11 Zelis R, Mansour EJ, Capone RJ, Mason DT. The cardiovascular effects of morphine. $\mathcal{F}$ Clin Invest 1974;54:1247-58.

12 Drew JH, Dripps RD, Comroe JH. Clinical studies on morphine. II. The effect of morphine on the circulation of man phine. II. The effect of morphine on the circulation of man ing. Anesthesiology 1946;7:44-61.

13 Rubin PC. Opioid peptides in blood pressure regulation in man. Clin Sci 1984;66:625-30.

14 Thomas M, Malmcrona R, Fillmore S, Shillingford J. Haemodynamic effects of morphine in patients with acute myocardial infarction. Br Heart f 1965;27:863-75.

15 Lowenstein E, Hallowell P, Levine FH, Daggett WM, Austen WG, Laver MB. Cardiovascular response to large doses of intravenous morphine in man. N Engl f Med 1969;281:1389-93

16 Drayton MR, Skidmore R. Vasoactivity of the the major cerebral arteries in newborn infants. Arch Dis Child 1987;62:236-40.

17 Evans N, Iyer P. Longitudinal changes in the diameter of the ductus arteriosus in ventilated preterm infants: correlation with respiratory outcomes. Arch Dis Child Fetal Neonatal Ed 1995;72:F156-61. 